\title{
Biocidal capability optimization in organic-inorganic nanocomposites based on titania
}

María L. Cerrada, ${ }^{a}$ Cristina Serrano, ${ }^{a}$ Manuel Sánchez-Chaves, ${ }^{a}$ Marta Fernández-García, ${ }^{*, a}$ María Alicia de Andrés, ${ }^{b}$ Rafael J. Riobóo, ${ }^{b}$ Fernando Fernández-Martín, ${ }^{c}$ Anna Kubacka, ${ }^{d}$ Manuel Ferrer, ${ }^{d}$ Marcos Fernández-Garcia, ${ }^{*, d}$

a Instituto de Ciencia y Tecnología de Polímeros, CSIC, C/ Juan de la Cierva 3, 28006Madrid, Spain; E-mail: martafg@ictp.csic.es

${ }^{b}$ Instituto Ciencia de Materiales, CSIC, C/Sor Juan Inés de la Cruz 3, 28049-Madrid, Spain

c Instituto del Frío, CSIC, C/José Antonio Novais 10, 28040-Madrid, Spain

d Instituto de Catálisis y Petroleoquímica, CSIC, C/Marie Curie 2, 28049-Madrid, Spain; Email:mfg@icp.csic.es

Optimization of the interfacial agent content in biocidal organic-inorganic nanocomposites is analyzed in terms of their physico-chemical interface characteristics. The balance between the photochemistry (photo-killing) behavior and the thermal properties is achieved in the nanocomposites with an incorporation of 2 wt.-\% in inorganic nanoparticles $\left(\mathrm{TiO}_{2}\right)$ using a compatibilizer content ranging from 50 to $80 \mathrm{wt} . \%$ with respect to the titania amount.

\section{Introduction}

The use of photocatalytic semiconductor oxides emerges as a successful technology to struggle against biological risks in these days that great concerns exist to guarantee the safety of products related to foods/beverages packaging or containers for biomedical/pharmaceutical materials/devices. $\mathrm{TiO}_{2}$-Anatase is by far the most widely used photocatalyst, being a wide band-gap $(3.2 \mathrm{eV})$ semiconductor that under UV illumination generates energy-rich electron-hole pairs able to degrade cell components of microorganisms rendering innocuous products (1). Moreover, none weakness with respect to the microorganism nature (bacteria, virus, fungus, etc.) is nowadays known. Consequently, its incorporation as a constituent in polymeric multicomponent materials could be a future alternative within goods packaging field.

Isotactic polypropylene (iPP) is one of the most widely utilized polyolefin. Among other applications are included its industrial use as material in areas of food packaging and medical supplies. Its non-polar macromolecular nature does, however, make the incorporation of functionalized oligomers as compatibilizers essential while hosting inorganic components. There are numerous works related to the incorporation of maleic anhydride (MAH) modified PP oligomers (PP-g-MAH) to help dispersion of particles in composites resulting in a greater reinforcement effect of the clays or silica oxide-type materials $(2,3)$. 
Vladimirov et al. (4) found that the average size of silica particle aggregates within an iPP matrix increased as silica contents did, whilst they became smaller using higher amounts of PP-g-MAH. Therefore, a crucial task when nanocomposite materials with improved performance are developed is to appropriately choose the characteristics and amounts of the different components.

This work describes optimization of the interfacial agent content required for preparation using a cost-effective melting processing of novel organic-inorganic nanocomposites based on titania and isotactic polypropylene with a very efficient antimicrobial activity towards both gram-negative (Pseudomonas aeruginosa) and gram-positive bacteria (Enterococcus faecalis). The importance of optimizing the compatibilizer content lies in attaining the perfect $\mathrm{TiO}_{2}$-anatase dispersion into the iPP matrix required to exhibit extraordinary biocide characteristics without damaging the mechanical performance of the nanocomposites. An

earlier survey clearly demonstrated that the minimum amount of $\mathrm{TiO}_{2}$ nanoparticles for achieving an effective and entire elimination of micro-organisms in several materials is around $2 \%$ in weight $(5,6)$ Therefore, an in-deep study of the biocidal capability of the system as well as its physicochemical background are performed as function of compatibilizer agent incorporation, which allows a continuous-like oxide-polymer contact at interface.

\section{Experimental Section}

Nanocomposite preparation: The $\mathrm{TiO}_{2}$ component (characteristic primary particle size below $10 \mathrm{~nm}$ ) was prepared using microemulsion synthetic route by addition of titanium (IV) isopropoxide (Aldrich) to an inverse emulsion containing an aqueous phase dispersed in $n$ heptane (Panreac), using Triton X-100 (Aldrich) as surfactant and 1-hexanol (Aldrich) as cosurfactant. The mixture was stirred for $24 \mathrm{~h}$, centrifuged, decanted, rinsed under stirring five consecutive times with methanol (twice), water (twice) and acetone (one) to eliminate any portion from the organic and surfactant media, dried at $110 \stackrel{\circ}{\mathrm{C}}$ for $24 \mathrm{~h}$ and calcined at $500 \stackrel{\circ}{ } \mathrm{C}$ for $2 \mathrm{~h}$. A commercially available metallocene-catalyzed isotactic polypropylene, iPP (Basell Metocene X50081: melt flow index of $60 \mathrm{~g} / 10 \mathrm{~min}$ at $230{ }^{\circ} \mathrm{C} / 2.16 \mathrm{~kg}$, ASTM D1238), meeting FDA requirements for food contact (Federal Regulations, 21 CFR 177.1520), was used as polymeric matrix in the preparation of these $\mathrm{iPP}^{-\mathrm{TiO}_{2}}$ nanocomposites. PP-g-MAH, polypropylene wax partially grafted with maleic anhydride, was used as interfacial agent (Licomont ${ }^{\circledR}$ AR 504 fine grain from Clariant) in compositions of 0, 30, 50 and 80 wt.-\% with respect to the content of 2 wt.- $\%$ in $\mathrm{TiO}_{2}$ nanoparticles $(0,0.6,1$ and 1.6 overall wt.-\% loadings, respectively). The resultant three-component nanocomposites were labeled as iPPxT2 along manuscript, being $x$ the compatibilizer content related to the $2 \mathrm{wt} . \%$ composition in $\mathrm{TiO}_{2}$. These biocidal nanocomposites were prepared through a straightforward melt processing in an internal mixer with volumetric capacity of $3 \mathrm{~cm}^{3}$ at 160 
${ }^{\circ} \mathrm{C}$ and at $60 \mathrm{rpm}$ for $5 \mathrm{~min}$, previous $\mathrm{TiO}_{2}$ sonication in an ultrasonic device to minimize the aggregation of nanoparticles and maximize the performance of resultant nanocomposites. After that, specimens were obtained as films (100 $\pm 5 \mu \mathrm{m}$ thickness) by compression molding in a Collin press between hot plates $\left(175^{\circ} \mathrm{C}\right)$ at a pressure of $1.5 \mathrm{MPa}$ for $5 \mathrm{~min}$. A quench was applied to the different films.

Nanocomposites characterization: Transmission electron microscopy was performed at room temperature in a $200 \mathrm{Kv}$ JEM-2000 FX JEOL microscope to analyze material homogeneity. Samples were embedded in Spurr resine (cured at $60 \stackrel{\circ}{ } \mathrm{C}$ for $48 \mathrm{~h}$ ) to obtain parallel cuts of the films surface in thin sections $(80 \mathrm{~nm})$ by ultramicrotomy (Reichert-Jung Ultracut E). Specimens were then picked up on cooper grids and coated with a thin layer of carbon graphite (MED 010 Balzers evaporator) to improve heat conduction. The crystalline characteristics of nanocomposites were examined by wide-angle X-ray scattering, WAXS, in reflection mode at room temperature using a Bruker AXS: D8 Advance diffractometer, Cu Ka radiation $(\lambda=1.5418 \AA)$ and a Vantec-1 detector. The scans were collected at a rate of $1 \% /$ min between $2 \theta$ values from 5 to $30^{\circ}$. The goniometer was calibrated with a standard of silicon. The X-ray determination of crystallinity degree, $f_{c}{ }^{\text {WAXS }}$, was performed by subtraction of the amorphous component comparing to a totally amorphous profile from an elastomeric PP sample. Studies at small angle region were performed in the synchrotron beamline A2 at Hasylab (Hamburg, Germany) ( $\lambda=1.50 \AA$ ) using a MAR CCD detector at a distance of 230 $\mathrm{cm}$ from the sample. SAXS detector was calibrated with the different orders of the long spacing of rat-tail cornea $(\mathrm{L}=65 \mathrm{~nm})$. The two-dimensional $X$-ray patterns were processed with the FIT2D program (ESRF) and converted into one-dimensional arrays after normalization for intensity of primary beam and subtraction of scattering of an empty sample.

The phase transitions on heating were analyzed by differential scanning calorimetry measurements performed in a Perkin Elmer DSC/TA7DX calorimeter connected to a cooling system and calibrated with different standards. Samples ( $10 \mathrm{mg})$ were scanned from -50 to $180{ }^{\circ} \mathrm{C}$ at $10{ }^{\circ} \mathrm{C} / \mathrm{min}$ under dry nitrogen $\left(20 \mathrm{~cm}^{3} / \mathrm{min}\right)$. Raman and photoluminescence measurements were carried out at room temperature with different laser lines of an $\mathrm{Ar}+-\mathrm{Kr}+$ laser: $333 \mathrm{~nm}+365 \mathrm{~nm}$, and $514 \mathrm{~nm}$. A home-made micro-Raman system was utilized, consisting on a Jobin-Yvon HR 460 monochromator, a $\mathrm{N}_{2}$ cooled CCD and Kaiser SuperNotch-Plus filters to suppress the elastic scattered light at $514 \mathrm{~nm}$. The excitation light was focused on samples with an Olympus microscope (except for 333 and $365 \mathrm{~nm}$ UV laser lines), which was also used to collect the scattered light. Spectra were corrected by the instrumental function recorded with a calibrated white source and $\mathrm{aaF}_{2}$ pellet. Raman spectra were normalized using the total intensity of the $\mathrm{C}-\mathrm{H}$ rocking vibrations. 
Microbiological tests: The microorganisms used in this study included two clinical isolates: Pseudomonas aeruginosa PAO clinical isolate PBCLOp11 from burn wound infections and Enterococcus faecalis clinical isolate brs30 from human biliary, both classified according to $16 \mathrm{~S}$ rRNA (unpublished). Bacterial cells were streaked from a glycerol stock onto a LB agar plate, grown overnight at $37^{\circ} \mathrm{C}\left(P\right.$. aeruginosa: $\left.\mathrm{OD}_{600} \sim 6.0\right)$ (no antibiotics) and subsequently used. To study the antimicrobial activity of films, a suspension containing $10 \mu \mathrm{l}$ of microbial cells (ca. $10^{9} \mathrm{cfu} \mathrm{ml}^{-1}$ ) suspended in $1 \mathrm{ml}$ broth solution was made (7). Aliquots of $1 \mathrm{ml}$ from these suspensions were added to a $4 \mathrm{ml}$ quartz cubic cell containing $1 \mathrm{ml}$ of sterilized water and the corresponding film under continuous stirring. The film-cell slurry was placed in the UV spectrometer chamber (UVIKON 930) and irradiated with a UV light at $280 \mathrm{~nm}$ for different time periods since $\mathrm{TiO}_{2}$ appears highly efficient under UV-B and UV-A wavelengths (280-380 nm). Care was put of using a sub-lethal, maximum radiation energy fluence of ca. 1 $\mathrm{kJ} \mathrm{m}^{-2}$ throughout the study. After irradiation and for different time intervals, aliquots of $100 \mu \mathrm{l}$ were transferred to a $10 \mathrm{ml}$ LB broth test tube. The order of cell dilution at this stage was $10^{-2}$. Loss of viability after each exposure time was determined by the viable count procedure on Luria Bertani agar plates after serial dilution $\left(10^{-2}\right.$ to $\left.10^{-5}\right)$. All plates were incubated at $37^{\circ} \mathrm{C}$ for $24 \mathrm{~h}$ prior to enumeration. A minimum of three experimental runs was performed to determine antimicrobial activity.

\section{Results and Discussion}

Figure 1 presents the TEM micrograph of the iPP80T2, nanocomposite with the highest compatibilizer amount. $\mathrm{TiO}_{2}$ is well-dispersed within the polymer exhibiting nanometric aggregates ranged from 10 to $200 \mathrm{~nm}$, with an average size (Feret diameter) of $80 \mathrm{~nm}( \pm 20$ $\mathrm{nm}$ ). Considering that the titania preparation makes use of an oxide previously calcined at high temperature to ensure the exclusive presence of the anatase polymorph and to strictly control its biocidal capabilities, the nanometric dispersion of the oxide is rather significant. This scenario is quite different to that shown by the specimen IPP0T2 where some microsized aggregates can be easily observed (Figure 1).

Figure 2 displays WAXS profiles at room temperature of the iPPxT2 nanocomposites, showing the five main diffractions characteristic of the a modification of iPP at $2 \theta$ values of $14.0,16.8,18.5,21.1$ and 21.7 degrees and that related to the 101 anatase diffraction at around 25.5\%. In addition, the $\mathrm{Y}$ iPP modification is partially developed within the nanocomposite iPP30T2 and, consequently, a small peak is seen at about $20^{\circ}$ corresponding to its (117) reflection (8). On the other hand, $f_{c}$ WAXs values are analogous for the different nanocomposites independently of the compatibilizer content (Table 1). The influence of $\mathrm{TiO}_{2}$ incorporation and interfacial agent composition are clearly noticeable at higher scale on the 
SAXS profiles and the long spacing estimated from them (Figure 3). An overlapping of two crystallite size distributions is observed in the IPP0T2, IPP30T2 and IPP50T2 specimens (see inset for iPP50T2) while iPP80T2 exhibits a broad but symmetric and more uniform distribution, fact that seems to indicate an improved interface adhesion between the different components with distinct electron density.

Table 1 also summarizes the characteristic glass and melting transition temperatures, $T_{g}$ and $T_{m}$, respectively. While $T_{m}$ values determined by DSC appear constant for the different interfacial agent contents, probably due to the crystallite improvement over heating, $T_{g}$ is shifted to higher temperatures indicating that mobility within amorphous regions is hindered as the compatibilizer amount increases. Assuming an intimate contact between the oxide and the interfacial agent (a direct outcome of the preparation method), data suggest the dominant presence of the inorganic component at the polymer amorphous phase within nanocomposites. The behavior at interface can be also studied by Raman, providing information about the inorganic component state in the nanocomposites. Figure 4 shows the Raman spectra in the selected fitting area for the distinct nanocomposites. The differences found in the stronger $E_{g}$ anatase peak at ca. $140-150 \mathrm{~cm}^{-1}$, in terms of peak intensity, reveal the effect of the compatibilizer content. Looking at peak height, the highest value corresponds to an interfacial agent content of $50 \%$ whereas if peak area is considered the optimal one is $80 \%$. These results indicate differences in scattering events due to subtle interface variation and further suggest the influence of the compatibilizer content in the nanocomposites through its interaction with the $\mathrm{TiO}_{2}$ nanoparticles.

The study of the UV excitation and de-excitation helps to understand the biocidal capabilities of these nanocomposites. The UV-visible sample spectra are shown in Figure 5A. The iPP spectrum displays a single feature at ca. $220 \mathrm{~nm}$ ascribed to chromophores (phenolic antioxidants and/or PP degradation products) coming from its industrial origin, while for nanocomposites, onset of a broad feature occurs in all cases at ca. $380 \mathrm{~nm}$, which is characteristic of the anatase- $\mathrm{TiO}_{2}$ component (9). No significant dissimilarities are found between the different iPPxTi2 nanocomposites. Considering that creation of electron-hole pairs occurs mainly in the $\mathrm{TiO}_{2}$ upon UV light absorption with wavelength above ca. $250 \mathrm{~nm}$, radiative de-excitation of these charge carriers can be followed by photoluminescence spectroscopy and potentially informs of charge handling processes on the whole nanocomposite system (10). Figure 5B depicts the photoluminescence spectra of samples showing strong similarities with the one exhibited by iPP. Two broad features are seen at ca. 425, $440 \mathrm{~nm}$, associated with the iPP matrix and the additive presence because of its industrial source (10), respectively. The inclusion of titania within the polymer enhances the 
radiative recombination pathway and causes the formation of an additional broad contribution centered at ca. 390-400 nm. This oxide-born feature is practically imperceptible for iPP30T2 but becomes visible for iPP50T2 and more significant for iPP80T2. As anatase- $\mathrm{TiO}_{2}$ is an indirect band gap semiconductor, band edge luminescence is very difficult to observe due to the inherent low probability of indirect transitions. In nanometric anatase- $\mathrm{TiO}_{2}$, near band edge luminescence is attributed to oxygen vacancies with two trapped electrons, i.e. F centers (11). These are likely related to surface states that are activated/enhanced only when compatibilizer allows a smooth interface contact between components. We detect charge transfer among components which, according to their band(s) gap and position, may include exciton (from charge originated at the organic component) and/or hole (from the inorganic component) separation, leaving holes into organic-like electronic states and electrons at the inorganic-like electronic states. As UV spectroscopy shown, charge carriers are dominantly generated at the inorganic component for light photons above $250 \mathrm{~nm}$ and, according to the photoluminescence results, could subsequently suffer an efficient charge separation process if compared with that occurring in the oxide alone. Therefore, a fraction of holes reaches the nanocomposite surface (from the bulk position of the inorganic component) and is involved in the microorganism photo-killing processes. There is thus an enhancement of light-induced surface charge carrier (e.g. hole) density at the surface of the nanocomposite films as compatibilizer amount increases. The combined SAXS/Raman analysis indicates that the improvement of the organic-inorganic interaction at interface with compatibilizer content is the key of this phenomenon, facilitating the charge separation process for loadings above $50 \mathrm{wt}$ \%.

Moreover, AFM micrographs and EPR measurements with probe molecules (oxygen) (results not shown) do not detect oxide existence at surface, indicating its dominant presence at the bulk of the material, this feature being a direct consequence of the preparation method. Therefore, there is not leaching of the nanocomposite to the aqueous phase when antimicrobial tests are performed.

A preliminary analysis established that titania nanoparticle-polypropylene nanocomposites with different $\mathrm{TiO}_{2}$ contents possesses an unprecedented power for destruction of regular bacteria, as B. stearothermophilus, E. coli, S. aureus and P. jadini, compared with other biocidal agents. The microorganisms here evaluated are $P$. aeruginosa and $E$. faecalis, since both microbes cause infections and serious illness and are widely present in the environment. Furthermore, $P$. aeruginosa is known as one of the most drug and vaccine-resistant microorganism. Moreover, we have used antibiotic-resistant and clinically isolated strains, magnifying the interest of the results. Blank experiments in presence of the iPP matrix demonstrate the relative innocuousness of UV radiation, a maximum of ca. 1.5 logreductions (see Figure 6). Incorporation of $\mathrm{TiO}_{2}$ has an important impact on the cell 
inactivation exhibited by the nanocomposites with respect to the blank test (measuring UV influence in presence of neat iPP). Accordingly, an initial increase of elimination velocity is clearly observed as well as the further decrease of final log-reduction at the end of the experiments. The behavior of the nanocomposites under the two microorganisms tested shows some similarities. On one hand, the greatest initial reduction rate is observed in samples of the iPP50T2 nanocomposite and, on the other hand, the almost complete cell inactivation of both microorganisms is reached, accounting for a log-reduction of near 9 units, in IPP50T2 and iPP80T2 specimens. Consequently, the loss of effectiveness found in the iPP30T2 seems to be ascribed to the lowest compatibilization level existing in this specimen because of its small interfacial agent content. However, this killing level is commonly understood as being bactericidal and sufficient to maintain an appropriate safety control, helping in eliminating the need for sterilization or other aggressive treatment of foods (12). Moreover, the system does not suffer any appreciable inactivation and could be reused without significant differences with these results.

Evaluation of other biocidal agents permits to appreciate that the present systems display an unprecedented power for bacteria destruction although it has to be considered that in the investigations below discussed the conditions used and initial bacterial population may vary from one study to the other. In relation to $P$. aeruginosa, the maximum (8.0 log-reduction/0.5 h) can be compared with those observed using $\mathrm{TiO}_{2}$ either as a powder (Degussa P25; 3.5 log-reduction/0.67 h) (13) or supported on Plexiglas (5.4 log-reduction/1 h) (14) and ethylene-vinyl alcohol copolymer (EVOH; 8.3 log-reduction/0.5 h) (5). Comparison with results using Ag-based systems as commercial $A g I O N \otimes$ coating stain steel (1.6 logreduction/4 h) (15); AgBr particles coating poly(vinyl pyridine) (max. 4 log-reduction) (16); NO on silica (4 log-reduction/1.5 h) (17); poly(alkylammonium) coatings on polyurethanes (4.4 log-reduction/0.5 h) (18); or simple chemicals like glutaraldehyde, formaldehyde, $\mathrm{H}_{2} \mathrm{O}_{2}$, phenol, cupric ascorbate or sodium hypochlorite (all below 6 log-reduction/0.5 h) (19) highlights the potential of our systems.

Concerning E. faecalis, it is well-known that this Gram positive bacterium can cause lifethreatening infections in humans and its thicker and more compact cell wall makes its destruction difficult by far other microorganisms. The obtained results (ca. 9 log-reduction/0.5 h) can be compared with water suspensions of $\mathrm{TiO}_{2}$ promoted with $\mathrm{Pt}(\mathrm{IV}$ ) salts (ca. 6 logreduction/0.5 h) (20); $\mathrm{TiO}_{2}$ supported on $\mathrm{EVOH}$ (6.3 log-reduction/0.5 h) (5) or $\mathrm{Ni}-\mathrm{TiO}_{2}$ nanocomposite coatings (2 log-reduction for extended period of times) (21). Other biocidal agents based on chemicals as trichlorosan on styrene-acrylate copolymers (initial rate enhancement below 2 with respect to the copolymer alone) (22); organometallic complexes leading to oxygen radical formation (3.5 log-reduction/4h) (23); or UV-treated Nylon (1.8 log- 
reduction/6 h) (24) provide further support to the assertion of the excellent functioning of the organic-inorganic nanocomposite films here described.

Summing up, the influence of PP-g-MAH content in the polymer/oxide crystalline characteristics, evaluated by WAXD and DSC, is rather insignificant for the different nanocomposites. However, the mobility of polymer amorphous regions is hindered leading to a slight improvement in thermal properties as compatibilizer content increases. These latest features seem to indicate a better adhesion at nanoparticle-polymer interfaces with contents of interfacial agent higher than $30 \%$ that appears corroborated by an enhancement of structural homogeneity of the interface according to SAXS and Raman. Differences also concern to the extraordinary powerful antimicrobiological activity exhibited by these nanocomposites, which is markedly faster for the iPP50T2 specimen. In relation to the final log-reduction reached, the iPP50T2 and iPP80T2 nanocomposites show analogous values, being higher than those observed in iPP30T2 for the two microorganisms. Photoluminiscence measurements support the presence of oxide-born charge carriers in the materials with the two highest PP-g-MAH compositions that efficiently interact and kill pernicious microorganisms and correlate well with the degree of nanoparticle-polymer interface adhesion. To conclude, it can be said that the ideal interfacial agent content for obtaining the most effective nanocomposite ranges from 50 to $80 \mathrm{wt} .-\%$.

\section{Acknowledgements}

A. Kubacka and C. Serrano are acknowledged to CSIC and MEC for financial supports (I3P postdoctoral and FPU predoctoral grants, respectively). Funding of CSIC is acknowledged (PIF200580F0101, PIF200560F0102, PIF200560F103 and PIF200570F104 projects). The synchrotron work was supported by the European Community - Research Infrastructure Action under the FP6 "Structuring the European Research Area" Programme (through the Integrated Infrastructure Initiative "Integrating Activity on Synchrotron and Free Electron Laser Science"), contract RII3-CT-2004-506008 (IA-SFS). We thank the help of Dr. Funari (beamline A2, Hasylab).We also thank to Basell and Clariant the supply of iPP and PP-g$M A H$, respectively.

\section{Literature cited}

(1) Carp, O.; Huisman, C. L.; Reller, A., Photoinduced reactivity of titanium dioxide. Prog. Solid State Chem. 2004, 32, (1-2), 33-177. 
(2) Reichert, P.; Nitz, H.; Klinke, S.; Brandsch, R.; Thomann, R.; Mulhaupt, R., Poly(propylene)/organoclay nanocomposite formation: Influence of compatibilizer functionality and organoclay modification. Macromol. Mater.Eng. 2000, 275, (2), 8-17.

(3) Mishra, J. K.; Hwang, K.-J.; Ha, C.-S., Preparation, mechanical and rheological properties of a thermoplastic polyolefin (TPO)/organoclay nanocomposite with reference to the effect of maleic anhydride modified polypropylene as a compatibilizer. Polymer 2005, 46, (6), 19952002.

(4) Vladimirov, V.; Betchev, C.; Vassiliou, A.; Papageorgiou, G.; Bikiaris, D., Dynamic mechanical and morphological studies of isotactic polypropylene/fumed silica nanocomposites with enhanced gas barrier properties. Compos. Sci. Technol. 2006, 66, (15), 2935-2944.

(5) Kubacka, A.; Serrano, C.; Ferrer, M.; Lünsdorf, H.; Bielecki, P.; Cerrada, M. L.; Fernández-García, M.; Fernández-García, M., High-performance dual-action polymer-TiO nanocomposite films via melting processing. Nano Letters 2007, 7, (8), 2529-2534.

(6) Kubacka, A.; Cerrada, M. L.; Serrano, C.; Fernández-García, M.; Ferrer, M.; FernándezGarcía, M., Light-Driven Novel Properties of $\mathrm{TiO}_{2}$-Modified Polypropylene-Based Nanocomposite Films. J. Nanosci. Nanotechno. 2008, 8, (6), 3241-3246.

(7) Ferrer, M.; Soliveri, J.; Plou, F. J.; López-Cortés, N.; Reyes-Duarte, D.; Christensen, M.; Copa-Patiño, J. L.; Ballesteros, A., Synthesis of sugar esters in solvent mixtures by lipases from Thermomyces lanuginosus and Candida antarctica $B$, and their antimicrobial properties. Enzyme Microb. Technol. 2005, 36, (4), 391-398.

(8) Brückner, S.; Meille, S. V.; Petraccone, V.; Pirozzi, B., Polymorphism in isotactic polypropylene. Prog. Polym. Sci. 1991, 16, (2-3), 361-404.

(9) Fernández-García, M.; Martínez-Arias, A.; Hanson, J. C.; Rodríguez, J. A., Nanostructured Oxides in Chemistry: Characterization and Properties. Chem. Rev. 2004, 104, (9), 4063-4104.

(10) Ambid, M.; Teyssedre, G.; Mary, D.; Laurent, C.; Montanari, G. C., Optical Properties and Luminescence Behaviour of PP/Clay Nanocomposites. IEEJ T. Electr. Electr.: Fundamentals and Materials 2006, 126, (11), 1097-1104.

(11) Lei, Y.; Zhang, L. D.; Men, G. W.; Li, G. W.; Zhang, S. R.; Kshirsager, S. T., Preparation and Photoluminescence of Highly Ordered TiO2 Nanowire Arrays. Appl. Phys. Lett. 2001, 78, (8), 1125-1127.

(12) Gundermann, K.-O.; Rüden, H.; Sonntag, H.-G., Lehrbuch der Hygiene, G. Fischer Verlag, Stuttgart, 1991.

(13) Ibáñez, J. A.; Litter, M. I.; Pizarro, R. A., Photocatalytic bactericidal effect of $\mathrm{TiO}_{2}$ on Enterobacter cloacae: Comparative study with other Gram (-) bacteria. J. Photochem. Photobiol., A 2003, 157, (1), 81-85. 
(14) Kühn, K. P.; Chaberny, I. F.; Massholder, K.; Stickler, M.; Benz, V. W.; Sonntag, H.-G.; Erdinger, L., Disinfection of surfaces by photocatalytic oxidation with titanium dioxide and UVA light. Chemosphere 2003, 53, (1), 71-77.

(15) Cowan, M. M.; Abshire, K. Z.; Houk, S. L.; Evans, S. M., Antimicrobial efficacy of a silver-zeolite matrix coating on stainless steel. J. Ind. Microbiol. Biotechnol. 2003, 30, (2), 102-106.

(16) Sambhy, V.; MacBride, M. M.; Peterson, B. R.; Sen, A., Silver Bromide Nanoparticle/Polymer Composites: Dual Action Tunable Antimicrobial Materials. J. Am. Chem. Soc. 2006, 128, (30), 9798-9808.

(17) Hetrick, E. M.; Shin, J. H.; Stasko, N. A.; Johnson, C. B.; Wespe, D. A.; Holmuhamedov, E.; Schoenfisch, M. H., Bactericidal Efficacy of Nitric Oxide-Releasing Silica Nanoparticles. ACS Nano 2008, 2, (2), 235-246.

(18) Kurt, P.; Wood, L.; Ohman, D. E.; Wynne, K. J., Highly Effective Contact Antimicrobial Surfaces via Polymer Surface Modifiers. Langmuir 2007, 23, (9), 4719-4723.

(19) Sagripanti, J.-L.; Bonifacino, A., Resistance of Pseudomonas aeruginosa to Liquid Disinfectants on Contaminated Surfaces before Formation of Biofilms. J. AOAC Int. 2000, 83, (6), 1415-1422.

(20) Mitoraj, D.; Jaczyk, A.; Strus, M.; Kisch, H.; Stochel, G.; Heczko, P. B.; Macyk, W., Visible light inactivation of bacteria and fungi by modified titanium dioxide Photochem. Photobiol. Sci. 2007, 6, (6), 642-648.

(21) Zhi-hong, Z.; Sakagami, Y.; Osaka, T., Corrosion Resistance and Antibacterial Activity Performances of $\mathrm{Ni}^{-\mathrm{TiO}_{2}}$ Composite Coatings. Chem. Lett. 1997, 26, (9), 909-911.

(22) Chung, D.; Papadakis, S. E.; Yam, K. L., Evaluation of a polymer coating containing triclosan as the antimicrobial layer for packaging materials. Int. J. Food Sci. Technol. 2003, 38, (2), 165-169.

(23) Villén, L.; Manjón, F.; García-Fresnadillo, D.; Orellana, G., Solar water disinfection by photocatalytic singlet oxygen production in heterogeneous medium. Appl. Catal., B 2006, 69, (1-2), 1-9.

(24) Shearer, A. E. H.; Paik, J. S.; Hoover, D. G.; Haynie, S. L.; Kelley, M. J., Potential of an Antibacterial Ultraviolet-Irradiated Nylon Film. Biotechnol. Bioeng. 2000, 67, (2), 141-146. 
Table 1. Characteristics of polypropylene crystalline phase for the different iPPxT2 nanocomposites and for the iPP homopolymer: $\mathrm{f}_{\mathrm{c}}{ }^{\text {WAXS }}$ (crystallinity degree determined by WAXS at room temperature); $\mathrm{T}_{\mathrm{g}}$ : glass transition temperature; $\mathrm{T}_{\mathrm{m}}$ : melting temperature; $\Delta \mathrm{H}_{\mathrm{m}}$ : melting enthalpy.

\begin{tabular}{|c|c|c|c|c|}
\hline Sample ${ }^{[a]}$ & $\mathrm{T}_{\mathrm{g}}\left({ }^{\circ} \mathrm{C}\right)$ & $\mathrm{T}_{\mathrm{m}}\left({ }^{\circ} \mathrm{C}\right)$ & $\Delta H_{m}(\mathbf{J} / \mathbf{g})$ & $\mathbf{f}_{c}$ WAXS \\
\hline iPP & 6 & 139 & 106 & 0.70 \\
\hline iPP30T2 & 5 & 139 & 104 & 0.65 \\
\hline ¡PP50T2 & 8 & 139 & 104 & 0.65 \\
\hline іРP80T2 & 10 & 139 & 108 & 0.65 \\
\hline
\end{tabular}



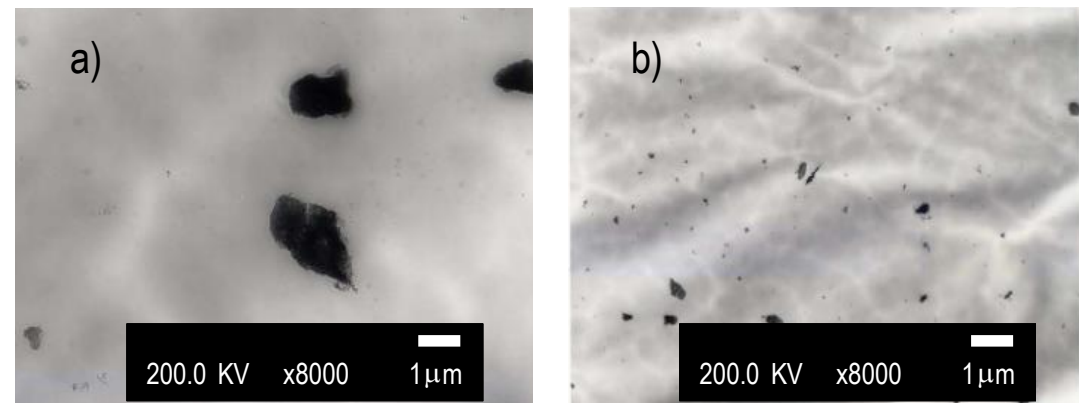

Figure 1. TEM micrographs of a) iPP0T2 and b) iPP80T2 nanocomposite.

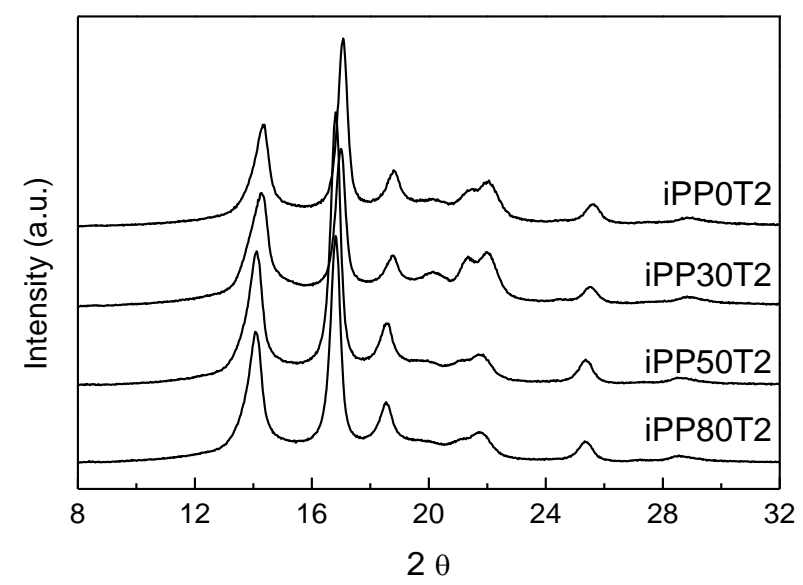

Figure 2. WAXS profiles at room temperature for the different iPPXT2 nanocomposites. 


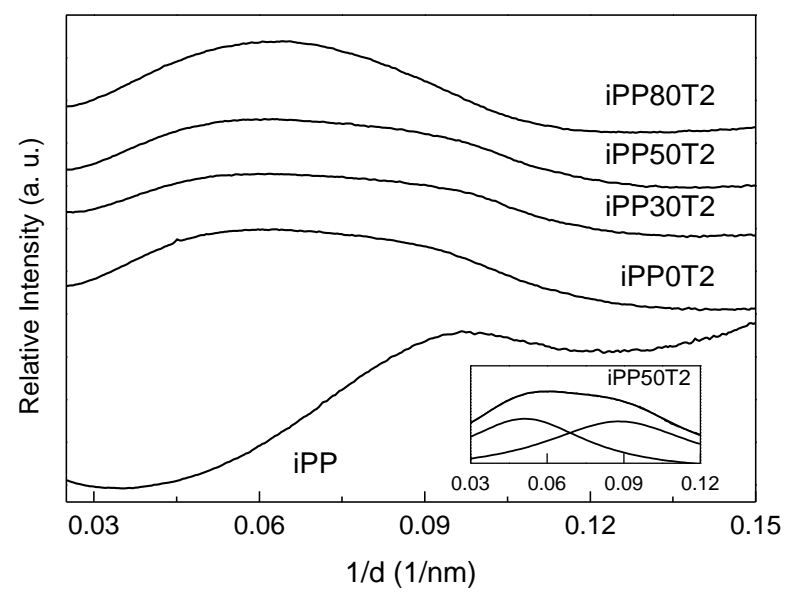

Figure 3. SAXS profiles at room temperature for iPPXT2 nanocomposites with different compatibilizer contents.

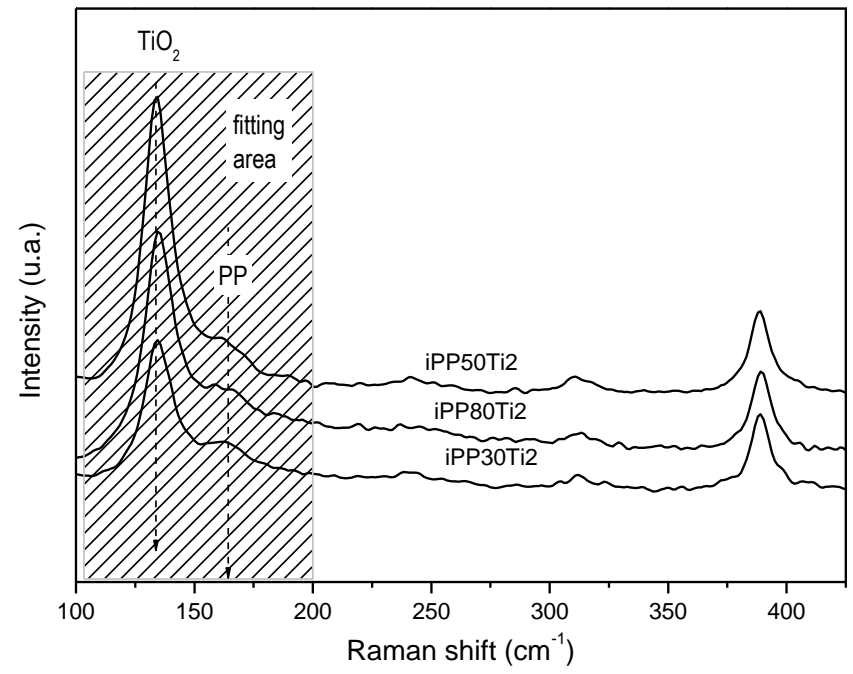

Figure 4. Raman spectra of iPPxT2 nanocomposites with different interfacial agent contents. 

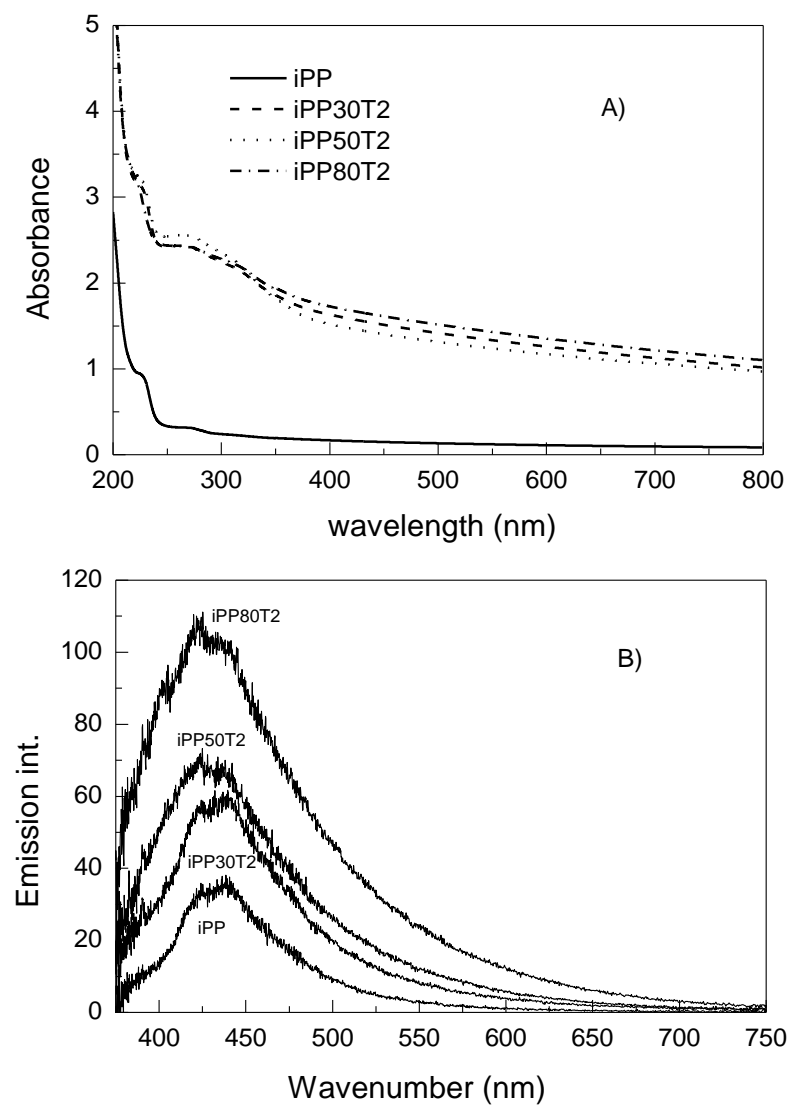

Figure 5. A) UV-visible and B) photoluminescence spectra of the reference polypropylene and iPPxT2 nanocomposite films. Excitation energy: $365 \mathrm{~nm}$. 

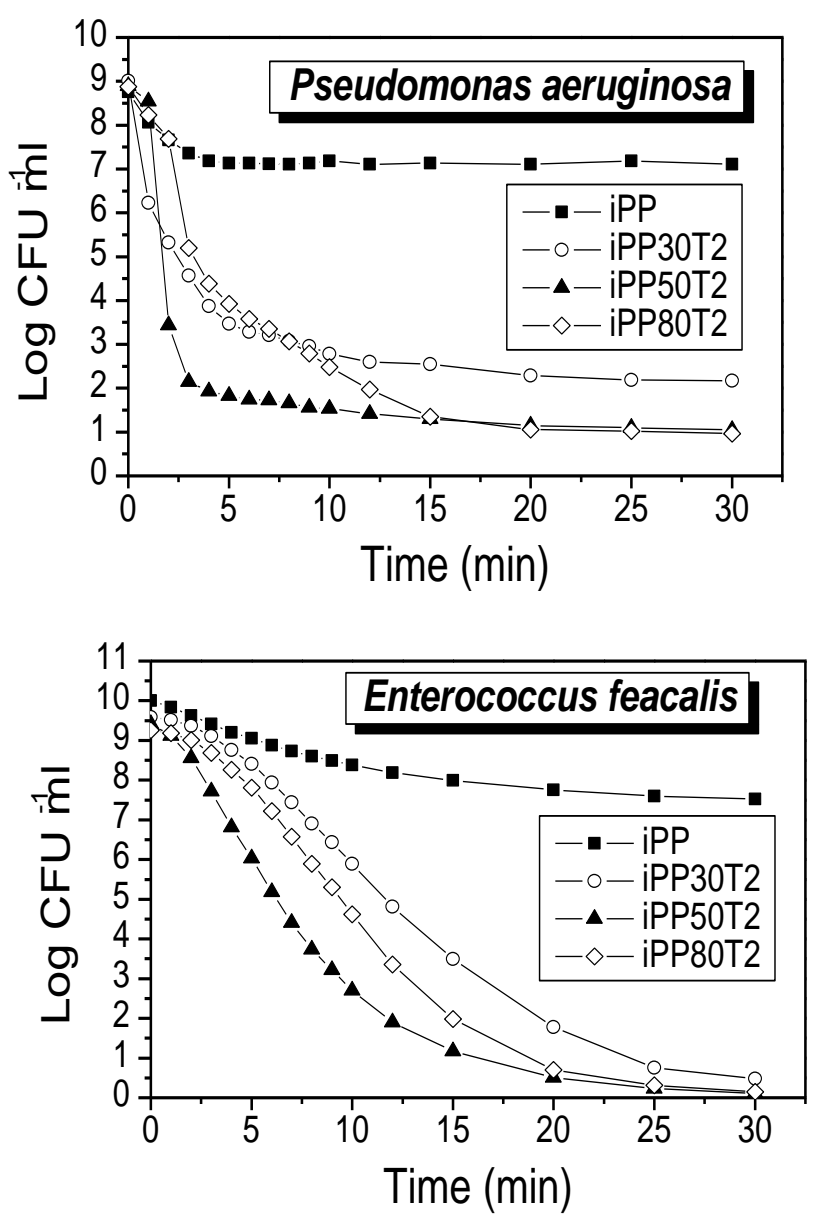

Figure 6. Process come-up logarithmic reduction of microorganism population suspended in LB medium. Survival curves of $P$. Aeruginosa and $E$. faecalis as function of irradiation time for iPP control and iPPxT2 samples. 
Table of Contents brief

Extraordinary biocidal properties in $\mathrm{iPP}_{-} \mathrm{TiO}_{2}$ nanocomposites are resulting from good interactions at interface which are favored by an appropriate compatibilizer content choice. 